\title{
Considerable practice variation in use of pathological high-risk T1-CRC criteria: Why, and how to do better?
}

\section{다)(1) $\odot$}

\author{
Authors \\ Mathieu Pioche1, Yutaka Saito² \\ Institutions \\ 1 Hépato-gastro-enterologie, Hospices Civils de Lyon, \\ hôpital Edouard Herriot, France \\ 2 Endoscopy division, National cancer center hospital, \\ Chuo-Ku, Tokyo, Japan \\ Bibliography \\ Endoscopy International Open 2020; 08: E1502-E1503 \\ DOI 10.1055/a-1243-0129 \\ ISSN 2364-3722 \\ (c) 2020. The Author(s).
}

\begin{abstract}
This is an open access article published by Thieme under the terms of the Creative Commons Attribution-NonDerivative-NonCommercial License, permitting copying and reproduction so long as the original work is given appropriate credit. Contents may not be used for commecial purposes, or adapted, remixed, transformed or built upon. (https://creativecommons.org/licenses/by-nc-nd/4.0/)
\end{abstract}

Corresponding author

Mathieu Pioche, MD, PhD, Service de gastro-entérologie et d'endoscopie digestive, Pavillon L, Hôpital Edouard Herriot, 5 place d'Arsonval, 69437 Lyon, France

Fax: +33472110147

mathieu.pioche@chu-lyon.fr
Although intramucosal adenocarcinomas are most often not considered T1 colorectal cancers (T1-CRC) in European series [1], they are, nonetheless, cancerous tumors ( $\mathrm{T} 1 \mathrm{a}$ ) owing to invasion into the chorion, and are considered as such by Japanese endoscopists. These lesions have no or negligible risk of lymph node metastasis and most Western endoscopists consider piecemeal endoscopic mucosal resection (EMR) suitable for them, dismissing the need for tumor-free resection margins. However, comparative data to evaluate the risk of missed information induced by piecemeal resection [2], including focal submucosal invasion, are still lacking. This underlines the discordance in the definition of malignant lesions that are present from the very first stage and that also exist at more advanced stages.

Low-risk CRC with submucosal invasion (low-risk T1-CRC) also is considered to have a negligible risk of lymph node metastasis when the following criteria are met: absence of vascular or lymphatic invasion, absence of significant budding, well or moderately differentiated tumor, and invasion depth in the submucosa $<1000$ microns. For these lesions, deep and lateral tumor-free resection margins $>1 \mathrm{~mm}$ are also expected. The presence of one of these criteria makes the lesion a high-risk T1-CRC owing to the associated non-negligible risk of lymph node metastasis.

However, the risk of each of these factors is not equivalent and it is easily understandable that the weight given the criteria in different multidisciplinary team discussion meetings is not equivalent, as demonstrated by the study reported by Gijsbers et al. [3]. For instance, the weight of vascular or lymphatic emboli is high as their presence increases the frequency of lymph node metastasis from $4 \%$ to $43 \%$ [4], with an odds ratio of 8 ad- justed based on invasion depth (95\% confidence interval [3.84; 17.1]) [5], therefore, emboli are taken into account by everyone. High-grade budding or undifferentiated components are also critical, increasing the frequency of lymph node metastasis from $16 \%$ to $70 \%$ with high-grade budding around the invasive foci [6] and from $11 \%$ to $45 \%$ with undifferentiated clusters [6]. Yet tumor budding was only considered by $57 \%$ of Dutch physicians involved in the study published in this issue, probably because this parameter is not required in pathology reports [3]. In Japan, budding is systematically described by pathologists and always considered to define low- or high-risk T1-CRC, as it is in expert centers in France, but probably not in all other pathology departments. Nevertheless, systematic description of the budding status is indispensable and should become a quality criterion in pathology reports to guide patient management. A point to consider is that detection of budding may vary among pathologists, notably according to whether immunochemistry was used. Therefore, it seems important to ensure the performance of pathologists in this regard before making this criterion a prerequisite.

Conversely, isolated depth of invasion > 1000 microns in the submucosa is probably not an independent risk factor for lymph node metastasis [7,8] as was previously believed [9], and how much weight to give it in decision-making about further revision surgery after EMR is debatable [7]. For that reason, it seems less important that this parameter is considered by fewer than half the physicians in the study [3], especially because a micrometer is an expensive piece of equipment that is probably not available in all pathology departments. 
Although a 4-cm margin is associated with better survival in T3 and T4 rectal cancers [10], the rationale for a margin that is a minimum of $1 \mathrm{~mm}$ laterally and in depth is not easily understood. Budding or emboli are usually in close proximity to the invasive components, and to our knowledge, no evidence exists regarding the clinical relevance of the information lost with margins $<1 \mathrm{~mm}$. Because of that lack of data, not all endoscopists are concerned about achieving 1-mm margins, but there is consensus about the necessity of $\mathrm{R} 0$ resection.

To summarize, risks associated with the high-risk T1-CRC group are very variable, depending on the criteria applied to assess them. Some criteria, such as the presence of emboli, are widely used by physicians, whereas other criteria, such as depth of invasion or size of margins, are associated with more questionable risk, which may justify the abandonment of them by some endoscopists. The description of all parameters by pathologists seems to be a necessary prerequisite if they are 3 to be used widely in multidisciplinary team meetings.

\section{Competing interests}

The authors declare that they have no conflict of interest.

\section{References}

[1] Backes Y, Schwartz MP, Ter Borg F et al. Multicentre prospective evaluation of real-time optical diagnosis of $\mathrm{T} 1$ colorectal cancer in large non-pedunculated colorectal polyps using narrow band imaging (the OPTICAL study). Gut 2019; 68: 271-279
[2] Pioche M, Rivory J], Ter Borg F et al. Colorectal endoscopic submucosal dissection for all LSTs: histological information loss due to piecemeal EMR is no longer acceptable. Endosc Int Open 2019; 7: E1195E1196

[3] Gijsbers K, de graaf W, Moons L et al. High practice variation in risk stratification, baseline oncological staging and surveillance strategies for T1 colorectal cancers in the Netherlands. Endosc Int Open 2020: E1117-E1122

[4] Yim K, Won DD, Lee IK et al. Novel predictors for lymph node metastasis in submucosal invasive colorectal carcinoma. World J Gastroenterol 2017; 23: 5936ers i

[5] Yasue C, Chino A, Takamatsu M et al. Pathological risk factors and predictive endoscopic factors for lymph node metastasis of T1 colorectal cancer: a single-center study of 846 lesions. J Gastroenterol 2019; 54: 708-717

[6] Patel N, Vyas M, Celli R et al. Adverse histologic features in colorectal nonpedunculated malignant polyps with nodal metastasis. Am J Surg Pathol 2020; 44: 241-246

[7] Rönnow C-F, Arthursson V, Toth E et al. Lymphovascular Infiltration, not depth of invasion, is the critical risk factor of metastases in early colorectal cancer: retrospective population-based cohort study on prospectively collected data, including validation. Ann Surg 2020; 13 : doi: $10.1097 /$ SLA. 0000000000003854

[8] Suh JH, Han KS, Kim BC et al. Predictors for lymph node metastasis in T1 colorectal cancer. Endoscopy 2012; 44: 590-595

[9] Beaton C, Twine CP, Williams GL et al. Systematic review and meta-analysis of histopathological factors influencing the risk of lymph node metastasis in early colorectal cancer. Colorectal Dis Off J Assoc Coloproctology G B Irel 2013; 15: 788788y

[10] Ozawa H, Kotake K, Ike H et al. Prognostic Impact of the Length of the Distal Resection Margin in Rectosigmoid Cancer: An Analysis of the JSCCR Database between 1995 and 2004. J Anus Rectum Colon 2020; 4: 59-66 